Fixed Point Theory, 22(2021), No. 1, 205-218

DOI: $10.24193 /$ fpt-ro.2021.1.14

http://www.math.ubbcluj.ro/ nodeacj/sfptcj.html

\title{
IMPLICIT CONTRACTIONS FOR A SEQUENCE OF MULTI-VALUED MAPPINGS
}

\author{
BOSHRA HOSSEINI* AND ALIREZA KAMEL MIRMOSTAFAEE** \\ * Department of Pure Mathematics, School of Mathematical Sciences, \\ Ferdowsi University of Mashhad, Mashhad 91775, Iran \\ E-mail: bhosseini1395@gmail.com \\ ** Center of Excellence in Analysis on Algebric Structure, \\ Department of Pure Mathematics, \\ Ferdowsi University of Mashhad, P.O. Box 1159, Mashhad 91775, Iran \\ E-mail: mirmostafaei@ferdowsi.um.ac.ir \\ (Corresponding author)
}

\begin{abstract}
In the present paper, we define a new class of implicit contractions for a sequence of multi-valued mappings on a metric space endowed with a graph to obtain sufficient conditions for existence of common fixed points for this sequence. This will enable us to obtain a simultaneous generalization of various types of fixed point theorems for a sequence of multi-valued mappings. Moreover, multi-fractal operators related to these contractive mappings are considered.
\end{abstract}

Key Words and Phrases: Fixed points, multi-valued mappings, graph.

2020 Mathematics Subject Classification: 47H10, 47H04, 05C40, 54H25.

Acknowledgments. The authors would like to thank the editors and anonymous reviewer for their careful reading of the manuscript and useful suggestions.

\section{REFERENCES}

[1] M.R. Alfuraidan, Remarks on monotone multivalued mappings on a metric space with a graph, J. Inequal. Appl. 2015;202, doi:10.1186/s13660-015-0712-6.

[2] A. Amini-Harandi, Fixed point theory for set-valued quasi-contraction maps in metric spaces, Appl. Math. Lett., (2011), 1791-1794.

[3] S. Banach, Sur les operations dans les ensembles abstraits et leur application aux equations integrales, (French), Fund. Math., 3(1922), 133-181.

[4] Lj. B. Ciric, A genaralization of Banach's contraction principle, Proc. Am. Math. Soc., 45(1974), 267-273.

[5] N. Hussain, C. Vetro, F. Vetro, Fixed point results for $\alpha$-implicit contractions with application to integral equations, Nonlinear Anal.: Modelling and Control, 21(2016), no. 3, 362-378.

[6] J. Jachymski, The contraction principle for mappings on a metric space with a graph, Proc. Amer. Math. Soc., 136(2008), 1359-1373.

[7] M. Kikkawa, T. Suzuki, Three fixed point theorems for generalized contractions with constants in complete metric spaces, Nonlinear Anal., 69(2008), 2942-2949.

[8] A.K. Mirmostafaee, Coupled fixed points for mappings on a b-metric space with a graph, Math. Vesnik, 69(2017), no. 3, 214-225. 
[9] A.K. Mirmostafaee, Fixed point theorems for set-valued mappings in b-metric spaces, Fixed Point Theory, 18(2017), no. 1, 305-314.

[10] G. Mot, A. Petruşel, Fixed point theory for a new type of contractive multivalued operators, Nonlinear Anal., 70(2009), 3371-3377.

[11] S.B. Nadler Jr., Multi-valued contraction mappings, Pacific J. Math., 30(1969), 475-488.

[12] J.J. Nieto, R. Rodríguez-López, Contractive mapping theorems in partially ordered sets and applications to ordinary differential equations, Order, 22(2005), 223-239.

[13] J.J. Nieto, R. Rodríguez-López, Existence and uniqueness of fixed point in partially ordered sets and applications to ordinary differential equations, Acta Mathematica Sinica, 23(2007), no. 12, 2205-212.

[14] V. Popa, Fixed point theorems for implicit contractive mappings, Stud. Cerc. St. Ser. Mat. Univ. Bacău, 7(1997), 127-133.

[15] V. Popa, Some fixed point theorems for compatible mappings satisfying an implicit relation, Demonstratio Math., 32(1999), 157-163.

[16] O. Popescu, A new type of contractive multivalued operators, Bull. Sci. Math., 137(2013), 30-44.

[17] O. Popescu, G. Stan, A generalization of Nadler's fixed point theorem, Results Math., 72(2017), 1525-1534.

[18] A.C.M. Ran, M.C.B. Reurings, A fixed point theorem in partially ordered sets and some applications to matrix equations, Proc. Amer. Math. Soc., 132(2003), 1435-1443.

[19] B.E. Rhoades, A comparison of various definitions of contractive mappings, Trans. Amer. Math. Soc., 226(1977), 257-290.

[20] T. Suzuki, Nadler's fixed point theorem in $\nu$-generalized metric spaces, Fixed Point Theory Appl., (2017), 2017:18.

Received: November 28, 2018; Accepted: July 25, 2019. 